\title{
Connectivity Analysis of Vehicles in Highway with One Entry/Exit and One RSU
}

\author{
Yu Wang, Lei Zhang \\ School of Electrical and Information Engineering, Jiangsu University of Technology, Changzhou, China \\ Email:yuwang_edina@jsut.edu.cn,zhlei@jsut.edu.cn
}

How to cite this paper: Wang, Y. and Zhang, L. (2020) Connectivity Analysis of Vehicles in Highway with One Entry/Exit and One RSU. Advances in Pure Mathematics, 10, 433-446. https://doi.org/10.4236/apm.2020.108026

Received: July 5, 2020

Accepted: August 3, 2020

Published: August 6, 2020

Copyright $\odot 2020$ by author(s) and Scientific Research Publishing Inc. This work is licensed under the Creative Commons Attribution International License (CC BY 4.0).

http://creativecommons.org/licenses/by/4.0/

\begin{abstract}
In this paper, we consider a unidirectional highway road with one entry/exit uniformly distributed on the road interval. One road side unit (RSU) is located on the position of the entry/exit. We build an analytical model to study the network connectivity problem. In building the analytical model, we take into account several parameters, such as vehicle arrival rate, vehicle moving speed, vehicle communication radius, RSU communication radius, highway road length and the probability of vehicles driving through the entry/exit. The analytical model is verified by using simulation tools.
\end{abstract}

\section{Keywords}

Connectivity, Entry/Exit, RSU, Vehicular Network

\section{Introduction}

Network connectivity is one of the most fundamental issues in Vehicular Ad Hoc Networks (VANETs). A higher connectivity in VANETs can ensure the timeliness for various kinds of data transmission. The previous studies indicated that the entries/exits in highway scenario can affect the network connectivity [1] [2] and deploying RSUs on the entries/exits is an effective method to improve the network connectivity [3] [4]. As so far, there is no study that focuses on the network connectivity modeling of such scenario. Thus, it is necessary to build an analytical model to study the network connectivity of highway scenario with entries/exits and RSUs, and it is also interesting to analyze the impacts of several parameters on the network connectivity in such scenario.

In this paper, we build an analytical model to study the network connectivity of highway scenario with one entry/exit and one RSU. We consider a unidirectional highway road with one entry/exit uniformly distributed on the road in- 
terval. One RSU is located on the position of the entry/exit. In building the analytical model, we divide the highway road into several road intervals, and analyze both the connectivity of each road interval and the connectivity of neighbor road interval. Moreover, we take into account several parameters, such as vehicle arrival rate, vehicle moving speed, vehicle communication radius, RSU communication radius, highway road length and the probability of vehicles driving through the entry/exit. The analytical model is verified by using simulation tools, and the analytical model can be used to analyze the impacts of several parameters on the network connectivity.

The remainder of the paper is organized as follows. Section II reviews related work in the literature. Section III derives the connectivity analytical model. Section IV presents simulation results to verify the accuracy of the analytical model. Section V concludes this paper.

\section{Related Work}

Connectivity analysis for a highway scenario in a VANET has been studied in the literature [5] [6] [7]. Most of the present work studies the connectivity of highway scenario without considering entries/exits [5] [6] [7]. In [5], Neelakan$\tan$ et al. focused on the connectivity analysis of a VANET from a physical perspective and investigated the minimum transit power used by vehicles to guarantee network connectivity. In [6], Shao et al. investigated the connectivity probabilities for $\mathrm{V} 2 \mathrm{~V}$ and V2I communication scenarios in one-way and two-way platoon-based VANETs and designed a connectivity-aware MAC protocol. In [7], Kwon et al. modeled the 1-D network as geometric elements of lines and points and analyze the connectivity of the network using geometric probability. However, in all of the above work, the network connectivity was studied for a highway scenario without considering entries/exit. In [1], Khabazian et al. presented a connectivity analytical model for a highway scenario with multiple entries/exits, but without considering the deployment of RSUs. This work is on the basis of our previous work [2] which considers the two-way connectivity in highway scenario with one entry/exit.

\section{Connectivity Analysis}

In this section, we build an analytical model to calculate the network connectivity probability of highway scenario with one entry/exit and one RSU.

\subsection{Network Scenario}

Consider a unidirectional highway road scenario, as shown in Figure 1. The vehicles are moving on the highway road. One entry/exit is distributed on the highway road. One RSU is deployed on the position of the entry/exit. The communication radius of vehicles is denoted as $R_{v}$ and the communication radius of RSU is denoted as $R_{u}$, here assumed that $R_{u} \geq R_{v}$. The highway road interval is denoted as $[0, L]$, where $L$ represents the length of the highway road and 


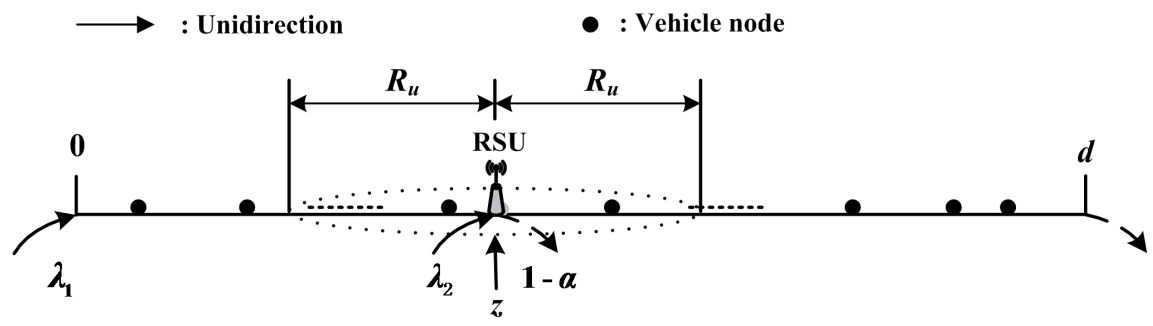

Figure 1. Basic network scenario.

$L \geq 2 R_{u}$. The entry/exit is denoted as $z$. Assume that $z$ follows uniform distribution on road interval $\left[R_{u}, L-R_{u}\right]$. The entry/exit divides the highway road interval into two sub-intervals which are represented as $[0, z]$ and $[z, L]$. The vehicle arrival process on $[0, z]$ is Poisson process with mean rate $\lambda_{1}$. When the vehicles on $[0, z]$ arriving at the position of the entry/exit, the vehicles can keep moving onto the next road interval $[z, L]$ with probability $\alpha(0 \leq \alpha \leq 1)$, or depart from the highway road at the entry/exit with probability $1-\alpha$. The vehicles moving on the road interval $[z, L]$ contains two parts: one is the vehicles from the road interval $[0, z]$ and the other is the new arriving vehicles from the entry/exit. The new arriving vehicles on the road interval $[z, L]$ are also Poisson process with mean rate $\lambda_{2}$. The vehicle speed is denoted as random variant $f_{v}$ which follows uniform distribution on interval $\left[v_{\min }, v_{\max }\right]$, where $v_{\min }$ and $v_{\max }$ respectively represents the minimum and the maximum value of the allowed moving speed for vehicles. The average value of the vehicle speed is expressed by $v=E\left[f_{v}\right]$, where $E[\cdot]$ represents mathematical expectation. According to the property of Poisson process, the vehicle arrival rates of $[0, z]$ and $[z, L]$ can be expressed by $\gamma_{1}$ and $\gamma_{2}$, where $\gamma_{1}=\lambda_{1} / v$ and $\gamma_{2}=\left(\alpha \cdot \lambda_{1}+\lambda_{2}\right) / v$. Therefore, the network connectivity in this paper is building an analytical model to calculate the connectivity probability of the vehicles in the network.

\subsection{Network Connectivity Probability}

Similar to Ref. [2], consider the two-way connectivity which requires that the vehicle and RSU can communicate with each other only and only if the distance between them is not larger than the vehicle communication radius. For ease of analysis, as shown in Figure 2, divide the interval $\left[z-R_{u}, z+R_{u}\right]$ into four sub-intervals which are denoted as $a_{1}, a_{2}, a_{3}$ and $a_{4}$, respectively. And the notations which are used after are listed as follows:

$H_{a}$ : the event that there are vehicles on road segment $a$.

$\bar{H}_{a}$ : the event that there is no vehicle on road segment $a$.

$C_{a}$ : the event that road segment $a$ is connected.

$\bar{C}_{a}$ : the event that road segment $a$ is disconnected.

$\operatorname{Pr}\{V\}$ : the probability that event $V$ occurs.

From Figure 2, it is obvious that the length of $a_{1}$ is not more than the communication radius of vehicle. If there are vehicles in $a_{1}$, the vehicles in $a_{1}$ is 


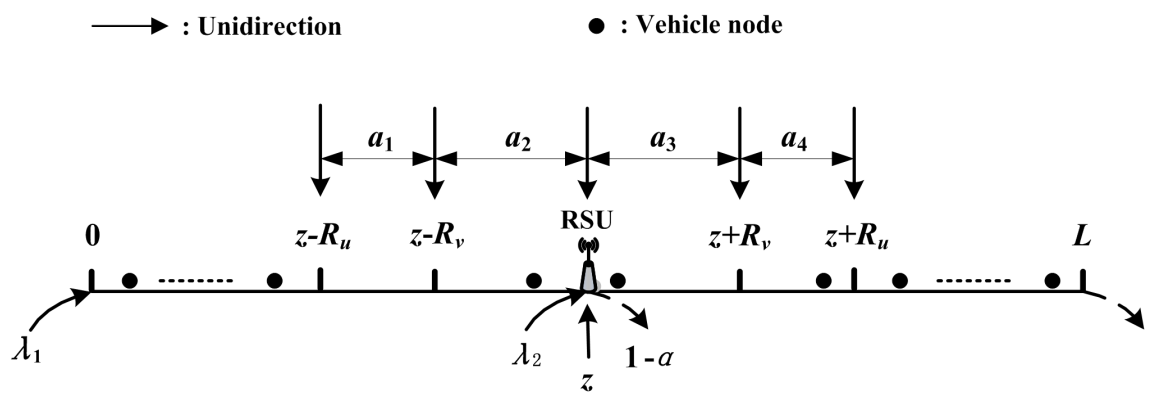

Figure 2. Analysis diagram.

connected. The connectivity of $a_{2}, a_{3}$ and $a_{4}$ is similar to $a_{1}$. Due to the influence of the entry/exit to the network connectivity, the connectivity of $a_{2}$ and $a_{3}$ is needed to be firstly considered. According to the case that whether there are vehicles on $a_{2}$ and $a_{3}$, we perform the analysis into following four sub-cases: 1) There are vehicles both on $a_{2}$ and $a_{3} ; 2$ ) There are vehicles on $a_{2}$, but there is no vehicle on $a_{3} ; 3$ ) There are vehicles on $a_{3}$, but there is no vehicle on $\left.a_{2} ; 4\right)$ There is no vehicle on $a_{2}$ and $a_{3}$.

The probabilities that there are vehicles on $a_{2}$ and $a_{3}$ are respectively given by

$$
\operatorname{Pr}\left\{H_{a_{2}}\right\}=1-\mathrm{e}^{-\gamma_{1} \cdot R_{v}}, \operatorname{Pr}\left\{H_{a_{3}}\right\}=1-\mathrm{e}^{-\gamma_{2} \cdot R_{v}} .
$$

The probabilities that there is no vehicle on $a_{2}$ and $a_{3}$ are respectively calculated by

$$
\operatorname{Pr}\left\{\bar{H}_{a_{2}}\right\}=1-\operatorname{Pr}\left\{H_{a_{2}}\right\}=\mathrm{e}^{-\gamma_{1} \cdot R_{v}}, \operatorname{Pr}\left\{\bar{H}_{a_{3}}\right\}=1-\operatorname{Pr}\left\{H_{a_{3}}\right\}=\mathrm{e}^{-\gamma_{2} \cdot R_{v}}
$$

1) There are vehicles both on $a_{2}$ and $a_{3}$.

It is seen from Figure 2, if there are vehicles on $a_{2}, a_{2}$ is connected for the case that the length of $a_{2}$ is not larger than the communication radius of vehicle and the distance between any two vehicles on $a_{2}$ is not larger than the communication radius of vehicle. The connectivity of $a_{3}$ is similar to that of $a_{2}$. If there are vehicles both on $a_{2}$ and $a_{3}$, the vehicles separately from $a_{2}$ and $a_{3}$ can two-way connect to each other by the RSU. For further analysis of the network connectivity, we divide a into four sub-cases.

a) There are vehicles both on $a_{1}$ and $a_{4}$.

In this case, we can calculate the probabilities that there are vehicles both on $a_{1}$ and $a_{4}$ as follows

$$
\operatorname{Pr}\left\{H_{a_{1}}\right\}=1-\mathrm{e}^{-\gamma_{1} \cdot\left(R_{u}-R_{v}\right)}, \operatorname{Pr}\left\{H_{a_{4}}\right\}=1-\mathrm{e}^{-\gamma_{2} \cdot\left(R_{u}-R_{v}\right)} .
$$

Then we analyze the connectivity of sub-interval $[0, z]$ and $[z, L]$.

When there are vehicles both on $\left[0, z-R_{u}\right]$ and $\left[z+R_{u}, L\right]$, if the vehicles on sub-interval $[0, z]$ are connected and the vehicles on sub-interval $[z, L]$ are connected, the road interval $[0, L]$ is connected. The probabilities that there are vehicles both on $\left[0, z-R_{u}\right]$ and $\left[z+R_{u}, L\right]$ are calculated as follows

$$
\operatorname{Pr}\left\{H_{\left[0, z-R_{u}\right]}\right\}=1-\mathrm{e}^{-\gamma_{1} \cdot\left(z-R_{u}\right)}, \operatorname{Pr}\left\{H_{\left[z+R_{u}, L\right]}\right\}=1-\mathrm{e}^{-\gamma_{2} \cdot\left(L-z-R_{u}\right)} .
$$


In this case, there is no entry/exit in sub-interval $[0, z]$ and sub-interval $[z, L]$. The connectivity probabilities of sub-interval $[0, z]$ and sub-interval $[z, L]$ are obtained according to Ref. [8]. In Ref. [8], for a highway road without entries and exits, if vehicle arrivals follow a Poisson process, the connectivity probability of the road is given by

$$
\begin{aligned}
\operatorname{Pr}\left\{\lambda_{v}, R_{v}, L^{\prime}\right\}= & \mathrm{e}^{-\lambda_{v} \cdot L^{\prime}} \sum_{j=0}^{\left\lfloor L^{\prime} / R_{v}\right\rfloor} \frac{(-1)^{j}}{j !}\left[\lambda_{v}\left(L^{\prime}-j R_{v}\right)\right]^{j-1} \\
& \times\left[j+\lambda_{v}\left(L^{\prime}-j R_{v}\right)\right] \mathrm{e}^{\lambda_{v} \cdot\left(L^{\prime}-j R_{v}\right)}
\end{aligned}
$$

where $L^{\prime}$ is the road length, $R_{v}$ is a vehicle's transmission radius, $\lambda_{v}$ is the vehicle arrival rate, and $\lfloor x\rfloor$ is the largest integer that is not larger than $x$. Thus, the connectivity probabilities of sub-interval $[0, z]$ and sub-interval $[z, L]$ are

$$
\operatorname{Pr}\left\{C_{[0, z]}\right\}=\operatorname{Pr}\left\{\gamma_{1}, R_{v}, z\right\}, \operatorname{Pr}\left\{C_{[z, L]}\right\}=\operatorname{Pr}\left\{\gamma_{2}, R_{v}, L-z\right\} .
$$

The connectivity probability of road interval $[0, L]$ is

$$
p_{1.1 .1}=\operatorname{Pr}\left\{H_{\left[0, z-R_{u}\right]}\right\} \cdot \operatorname{Pr}\left\{H_{\left[z+R_{u}, L\right]}\right\} \cdot \operatorname{Pr}\left\{C_{[0, z]}\right\} \cdot \operatorname{Pr}\left\{C_{[z, L]}\right\} \cdot
$$

When there are vehicles on $\left[0, z-R_{u}\right]$, but there is no vehicle on $\left[z+R_{u}, L\right]$, if the vehicles on sub-interval $[0, z]$ are connected and the vehicles on sub-interval $\left[z, z+R_{u}\right]$ are connected, the road interval $[0, L]$ is connected. The probability that there is no vehicle on $\left[z+R_{u}, L\right]$ is calculated as follows

$$
\operatorname{Pr}\left\{\bar{H}_{\left[z+R_{u}, L\right]}\right\}=1-\operatorname{Pr}\left\{H_{\left[z+R_{u}, L\right]}\right\}=\mathrm{e}^{-\gamma_{2} \cdot\left(L-z-R_{u}\right)} .
$$

The connectivity probability for the vehicles on $\left[z, z+R_{u}\right]$ is

$$
\operatorname{Pr}\left\{C_{\left[z, z+R_{u}\right]}\right\}=\operatorname{Pr}\left\{\gamma_{2}, R_{v}, R_{u}\right\} .
$$

In this case, the connectivity probability of road interval $[0, L]$ is

$$
p_{1.1 .2}=\operatorname{Pr}\left\{H_{\left[0, z-R_{u}\right]}\right\} \cdot \operatorname{Pr}\left\{\bar{H}_{\left[z+R_{u}, L\right]}\right\} \cdot \operatorname{Pr}\left\{C_{[0, z]}\right\} \cdot \operatorname{Pr}\left\{C_{\left[z, z+R_{u}\right]}\right\} .
$$

When there are vehicles on $\left[z+R_{u}, L\right]$, but there is no vehicle on $\left[0, z-R_{u}\right]$, if the vehicles on sub-interval $\left[z-R_{u}, z\right]$ are connected and the vehicles on sub-interval $[z, L]$ are connected, the road interval $[0, L]$ is connected. The probability that there is no vehicle on $\left[0, z-R_{u}\right]$ is

$$
\operatorname{Pr}\left\{\bar{H}_{\left[0, z-R_{u}\right]}\right\}=1-\operatorname{Pr}\left\{H_{\left[0, z-R_{u}\right]}\right\}=\mathrm{e}^{-\gamma_{1} \cdot\left(z-R_{u}\right)} .
$$

The connectivity probability for the vehicles on $\left[z-R_{u}, z\right]$ is

$$
\left[z-R_{u}, z\right] \operatorname{Pr}\left\{C_{\left[z-R_{u}, z\right]}\right\}=\operatorname{Pr}\left\{\gamma_{1}, R_{v}, R_{u}\right\} .
$$

In this case, the connectivity probability of road interval $[0, L]$ is

$$
p_{1.1 .3}=\operatorname{Pr}\left\{\bar{H}_{\left[0, z-R_{u}\right]}\right\} \cdot \operatorname{Pr}\left\{H_{\left[z+R_{u}, L\right]}\right\} \cdot \operatorname{Pr}\left\{C_{\left[z-R_{u}, z\right]}\right\} \cdot \operatorname{Pr}\left\{C_{[z, L]}\right\} \cdot
$$

When there is no vehicle on $\left[0, z-R_{u}\right]$ and $\left[z+R_{u}, L\right]$, if the vehicles on $\left[z-R_{u}, z\right]$ are connected and the vehicles on $\left[z, z+R_{u}\right]$ are connected, the 
road interval $[0, L]$ is connected. In this case, the connectivity probability of road interval $[0, L]$ is

$$
p_{1.1 .4}=\operatorname{Pr}\left\{\bar{H}_{\left[0, z-R_{u}\right]}\right\} \cdot \operatorname{Pr}\left\{\bar{H}_{\left[z+R_{u}, L\right]}\right\} \cdot \operatorname{Pr}\left\{C_{\left[z-R_{u}, z\right]}\right\} \cdot \operatorname{Pr}\left\{C_{\left[z, z+R_{u}\right]}\right\} \cdot
$$

Thus, the connectivity probability of road interval $[0, L]$ in a-1) is

$$
p_{1.1}=\operatorname{Pr}\left\{H_{a_{1}}\right\} \cdot \operatorname{Pr}\left\{H_{a_{4}}\right\} \cdot\left(p_{1.1 .1}+p_{1.1 .2}+p_{1.1 .3}+p_{1.1 .4}\right) .
$$

b) There are vehicles on $a_{1}$, but there is no vehicle on $a_{4}$.

In b), the probability that there is no vehicle on $a_{4}$ is

$$
\operatorname{Pr}\left\{\bar{H}_{a_{4}}\right\}=1-\operatorname{Pr}\left\{H_{a_{4}}\right\}=\mathrm{e}^{-\gamma_{2} \cdot\left(R_{u}-R_{v}\right)} .
$$

When there are vehicles both on $\left[0, z-R_{u}\right]$ and $\left[z+R_{u}, L\right]$, if the vehicles on sub-interval $[0, z]$ are connected, the vehicles on sub-interval $\left[z+R_{u}, L\right]$ are connected, and the vehicles separately from $a_{3}$ and $\left[z+R_{u}, L\right]$ are connected, the road interval $[0, L]$ is connected. Since there is no entry/exit in $\left[z+R_{u}, L\right]$, the connectivity probability of $\left[z+R_{u}, L\right]$ is

$$
\operatorname{Pr}\left\{C_{\left[z+R_{u}, L\right]}\right\}=\operatorname{Pr}\left\{\gamma_{2}, R_{v}, L-z-R_{u}\right\} .
$$

Next, we analyze the connectivity of vehicles separately from $a_{3}$ and $\left[z+R_{u}, L\right]$. According to the definition of two-way connectivity and the assumption that $R_{u} \geq R_{v}$. From Figure 2, we can easily obtain that in the case $R_{u}>2 R_{v}$, the distance between two vehicles which separately from $a_{3}$ and $\left[z+R_{u}, L\right]$ is larger than the communication radius of vehicles. In this case, the vehicles which separately from $a_{3}$ and $\left[z+R_{u}, L\right]$ have no chance to connect to each other, the road interval $[0, L]$ is disconnected. Otherwise, if $R_{u} \leq 2 R_{v}$, the vehicles which separately from $a_{3}$ and $\left[z+R_{u}, L\right]$ have chance to connect to each other. Thus, in the following analysis, we further assume that $R_{u} \leq 2 R_{v}$. When there are vehicles on $\left[z+R_{u}, z+2 R_{v}\right]$, if the vehicles separately from $a_{3}$ and $\left[z+R_{u}, z+2 R_{v}\right]$ are connected, $a_{3}$ and $\left[z+R_{u}, L\right]$ is connected. Otherwise, when there is no vehicle on $\left[z+R_{u}, z+2 R_{v}\right]$, the road interval $[0, L]$ is disconnected. The probability that there are vehicles on $\left[z+R_{u}, z+2 R_{v}\right]$ is

$$
\operatorname{Pr}\left\{H_{\left[z+R_{u}, z+2 R_{v}\right]}\right\}=1-\mathrm{e}^{-\gamma_{2} \cdot\left(2 R_{v}-R_{u}\right)} .
$$

According to Ref. [1], we can obtain that the connectivity probability of vehicles separately from $a_{3}$ and $\left[z+R_{u}, z+2 R_{v}\right]$ is

$$
\operatorname{Pr}\left\{C_{a_{3},\left[z+R_{u}, z+2 R_{v}\right]}\right\}=\frac{1}{2} \text {. }
$$

The connectivity probability of vehicles separately from $a_{3}$ and $\left[z+R_{u}, L\right]$ is

$$
\operatorname{Pr}\left\{C_{\left\{a_{3},\left[z+R_{u}, L\right]\right\}}\right\}=\operatorname{Pr}\left\{H_{\left[z+R_{u}, z+2 R_{v}\right]}\right\} \cdot \operatorname{Pr}\left\{C_{\left\{a_{3},\left[z+R_{u}, z+2 R_{v}\right]\right\}}\right\} .
$$

In this case, when $R_{u}>2 R_{v}$, the connectivity probability of road interval $[0, L]$ is 0 ; when $R_{u} \leq 2 R_{v}$, the connectivity probability of road interval $[0, L]$ is calculated as follows 


$$
\begin{aligned}
p_{1.2 .1}= & \operatorname{Pr}\left\{H_{\left[0, z-R_{u}\right]}\right\} \cdot \operatorname{Pr}\left\{H_{\left[z+R_{u}, L\right]}\right\} \cdot \operatorname{Pr}\left\{C_{[0, z]}\right\} \\
& \cdot \operatorname{Pr}\left\{C_{\left[z+R_{u}, L\right]}\right\} \cdot \operatorname{Pr}\left\{C_{\left\{a_{3},\left[z+R_{u}, L\right]\right\}}\right\} .
\end{aligned}
$$

When there are vehicles on $\left[0, z-R_{u}\right]$, but there is no vehicle on $\left[z+R_{u}, L\right]$, if vehicles on $[0, z]$ is connected, the road interval $[0, L]$ is connected. In this case, the connectivity probability of road interval $[0, L]$ is

$$
p_{1.2 .2}=\operatorname{Pr}\left\{H_{\left[0, z-R_{u}\right]}\right\} \cdot \operatorname{Pr}\left\{\bar{H}_{\left[z+R_{u}, L\right]}\right\} \cdot \operatorname{Pr}\left\{C_{[0, z]}\right\} \cdot
$$

When there are vehicles on $\left[z+R_{u}, L\right]$, but there is no vehicle on $\left[0, z-R_{u}\right]$, if the vehicles on $\left[z-R_{u}, z\right]$ are connected, the vehicles on $\left[z+R_{u}, L\right]$ are connected, and the vehicles separately from $a_{3}$ and $\left[z+R_{u}, L\right]$ are connected, the road interval $[0, L]$ is connected. In this case, the connectivity probability of road interval $[0, L]$ is

$$
\begin{aligned}
p_{1.2 .3}= & \operatorname{Pr}\left\{\bar{H}_{\left[0, z-R_{u}\right]}\right\} \cdot \operatorname{Pr}\left\{H_{\left[z+R_{u}, L\right]}\right\} \cdot \operatorname{Pr}\left\{C_{\left[z-R_{u}, z\right]}\right\} \\
& \cdot \operatorname{Pr}\left\{C_{\left[z+R_{u}, L\right]}\right\} \cdot \operatorname{Pr}\left\{C_{\left\{a_{3},\left[z+R_{u}, L\right]\right\}}\right\} .
\end{aligned}
$$

When there is no vehicle both in $\left[0, z-R_{u}\right]$ and $\left[z+R_{u}, L\right]$, if vehicles on $\left[z-R_{u}, z\right]$ are connected, the road interval $[0, L]$ is connected. In this case, the connectivity probability of road interval $[0, L]$ is

$$
p_{1.2 .4}=\operatorname{Pr}\left\{\bar{H}_{\left[0, z-R_{u}\right]}\right\} \cdot \operatorname{Pr}\left\{\bar{H}_{\left[z+R_{u}, L\right]}\right\} \cdot \operatorname{Pr}\left\{C_{\left[z-R_{u}, z\right]}\right\} .
$$

Thus, the connectivity probability of road interval $[0, L]$ in a-2) is

$$
p_{1.2}=\operatorname{Pr}\left\{H_{a_{1}}\right\} \cdot \operatorname{Pr}\left\{\bar{H}_{a_{4}}\right\} \cdot\left(p_{1.2 .1}+p_{1.2 .2}+p_{1.2 .3}+p_{1.2 .4}\right) .
$$

c) There are vehicles on $a_{4}$, but there is no vehicle on $a_{1}$.

In c), the probability that there is no vehicle on $a_{1}$ is

$$
\operatorname{Pr}\left\{\bar{H}_{a_{1}}\right\}=1-\operatorname{Pr}\left\{H_{a_{1}}\right\}=\mathrm{e}^{-\gamma_{1} \cdot\left(R_{u}-R_{v}\right)} .
$$

When there are vehicles both on $\left[0, z-R_{u}\right]$ and $\left[z+R_{u}, L\right]$, if vehicles on $[z, L]$ are connected, vehicles on $\left[0, z-R_{u}\right]$ are connected, and vehicles separately from $a_{2}$ and $\left[0, z-R_{u}\right]$ are connected, the road interval $[0, L]$ is connected. The probability that there are vehicles on $\left[0, z-R_{u}\right]$ is

$$
\operatorname{Pr}\left\{C_{\left[0, z-R_{u}\right]}\right\}=\operatorname{Pr}\left\{\gamma_{1}, R_{v}, z-R_{u}\right\} .
$$

The analysis for the connectivity probability of vehicles separately from $a_{2}$ and $\left[0, z-R_{u}\right]$ is similar to that of vehicles separately from $a_{3}$ and $\left[z+R_{u}, L\right]$. Therefore, when $R_{u}>2 R_{v}$, the connectivity of road interval $[0, L]$ is 0 ; when $R_{u} \leq 2 R_{v}$, the connectivity of road interval $[0, L]$ is calculated as follows

$$
\begin{aligned}
p_{1.3 .1}= & \operatorname{Pr}\left\{H_{\left[0, z-R_{u}\right]}\right\} \cdot \operatorname{Pr}\left\{H_{\left[z+R_{u}, L\right]}\right\} \cdot \operatorname{Pr}\left\{C_{[z, L]}\right\} \\
& \cdot \operatorname{Pr}\left\{C_{\left[0, z-R_{u}\right]}\right\} \cdot \operatorname{Pr}\left\{C_{\left\{a_{2},\left[0, z-R_{u}\right]\right\}}\right\}
\end{aligned}
$$

where 


$$
\begin{gathered}
\operatorname{Pr}\left\{C_{\left\{a_{2},\left[0, z-R_{u}\right]\right.}\right\}=\operatorname{Pr}\left\{H_{\left[z-2 R_{v}, z-R_{u}\right]}\right\} \cdot \operatorname{Pr}\left\{C_{\left\{a_{2},\left[z-2 R_{v}, z-R_{u}\right]\right\}}\right\}, \\
\operatorname{Pr}\left\{H_{\left[z-2 R_{v}, z-R_{u}\right]}\right\}=1-\mathrm{e}^{-\gamma_{1} \cdot\left(2 R_{v}-R_{u}\right)} . \\
\operatorname{Pr}\left\{C_{\left\{a_{2},\left[z-2 R_{v}, z-R_{u}\right]\right\}}\right\}=\frac{1}{2} .
\end{gathered}
$$

When there are vehicles on $\left[0, z-R_{u}\right]$, but there is no vehicle on $\left[z+R_{u}, L\right]$, if vehicles on $\left[z, z+R_{u}\right]$ are connected, vehicles on $\left[0, z-R_{u}\right]$ are connected, and vehicles separately from $a_{2}$ and $\left[0, z-R_{u}\right]$ are connected, the road interval $[0, L]$ is connected. In this case, the connectivity probability of road interval $[0, L]$ is

$$
\begin{aligned}
p_{1.3 .2}= & \operatorname{Pr}\left\{H_{\left[0, z-R_{u}\right]}\right\} \cdot \operatorname{Pr}\left\{\bar{H}_{\left[z+R_{u}, L\right]}\right\} \cdot \operatorname{Pr}\left\{C_{\left[z, z+R_{u}\right]}\right\} \\
& \cdot \operatorname{Pr}\left\{C_{\left[0, z-R_{u}\right]}\right\} \cdot \operatorname{Pr}\left\{C_{\left\{a_{2},\left[0, z-R_{u}\right]\right\}}\right\} .
\end{aligned}
$$

When there are vehicles on $\left[z+R_{u}, L\right]$, but there is no vehicle on $\left[0, z-R_{u}\right]$, if vehicles on $[z, L]$ are connected, the road interval $[0, L]$ is connected. In this case, the connectivity probability of road interval $[0, L]$ is

$$
p_{1.3 .3}=\operatorname{Pr}\left\{\bar{H}_{\left[0, z-R_{u}\right]}\right\} \cdot \operatorname{Pr}\left\{H_{\left[z+R_{u}, L\right]}\right\} \cdot \operatorname{Pr}\left\{C_{[z, L]}\right\} \text {. }
$$

When there is no vehicle both on $\left[0, z-R_{u}\right]$ and $\left[z+R_{u}, L\right]$, if vehicles on $\left[z, z+R_{u}\right]$ are connected, the road interval $[0, L]$ is connected. In this case, the connectivity probability of road interval $[0, L]$ is

$$
p_{1.3 .4}=\operatorname{Pr}\left\{\bar{H}_{\left[0, z-R_{u}\right]}\right\} \cdot \operatorname{Pr}\left\{\bar{H}_{\left[z+R_{u}, L\right]}\right\} \cdot \operatorname{Pr}\left\{C_{\left[z, z+R_{u}\right]}\right\} \cdot
$$

Thus, the connectivity probability of road interval $[0, L]$ in a-3) is

$$
p_{1.3}=\operatorname{Pr}\left\{\bar{H}_{a_{1}}\right\} \cdot \operatorname{Pr}\left\{H_{a_{4}}\right\} \cdot\left(p_{1.3 .1}+p_{1.3 .2}+p_{1.3 .3}+p_{1.3 .4}\right) \text {. }
$$

d) There is no vehicle on $a_{1}$ and $a_{4}$.

In $\mathrm{d}$ ), for analyzing the connectivity of road interval $[0, L]$, we only need to consider the case that whether there are vehicles on $\left[0, z-R_{u}\right]$ and $\left[z+R_{u}, L\right]$.

When there are vehicles both on $\left[0, z-R_{u}\right]$ and $\left[z+R_{u}, L\right]$, if vehicles on $\left[0, z-R_{u}\right]$ are connected, vehicles on $\left[z+R_{u}, L\right]$ are connected, vehicles separately from $a_{2}$ and $\left[0, z-R_{u}\right]$ are connected, and vehicles separately from $a_{3}$ and $\left[z+R_{u}, L\right]$ are connected, the road interval $[0, L]$ is connected. In this case, when $R_{u}>2 R_{v}$, the connectivity probability of vehicles separately from $a_{2}$ and $\left[0, z-R_{u}\right]$ is 0 , the connectivity probability of vehicles separately from $a_{3}$ and $\left[z+R_{u}, L\right]$ is 0 , and the connectivity probability of road interval $[0, L]$ is 0 . When $R_{u} \leq 2 R_{v}$, the connectivity probability of road interval $[0, L]$ is

$$
\begin{aligned}
p_{1.4 .1}= & \operatorname{Pr}\left\{H_{\left[0, z-R_{u}\right]}\right\} \cdot \operatorname{Pr}\left\{H_{\left[z+R_{u}, L\right]}\right\} \cdot \operatorname{Pr}\left\{C_{\left[z+R_{u}, L\right]}\right\} \\
& \cdot \operatorname{Pr}\left\{C_{\left[0, z-R_{u}\right]}\right\} \cdot \operatorname{Pr}\left\{C_{\left\{a_{2},\left[0, z-R_{u}\right]\right\}}\right\} \cdot \operatorname{Pr}\left\{C_{\left\{a_{3},\left[z+R_{u}, L\right]\right\}}\right\} .
\end{aligned}
$$

When there are vehicles on $\left[0, z-R_{u}\right]$, but there is no vehicle on $\left[z+R_{u}, L\right]$, 
if vehicles on $\left[0, z-R_{u}\right]$ are connected, and vehicles separately from $a_{2}$ and $\left[0, z-R_{u}\right]$ are connected, the road interval $[0, L]$ is connected. In this case, the connectivity probability of road interval $[0, L]$ is

$$
p_{1.4 .2}=\operatorname{Pr}\left\{H_{\left[0, z-R_{u}\right]}\right\} \cdot \operatorname{Pr}\left\{\bar{H}_{\left[z+R_{u}, L\right]}\right\} \cdot \operatorname{Pr}\left\{C_{\left[0, z-R_{u}\right]}\right\} \cdot \operatorname{Pr}\left\{C_{\left\{a_{2},\left[0, z-R_{u}\right]\right\}}\right\} .
$$

When there are vehicles on $\left[z+R_{u}, L\right]$, but there is no vehicle on $\left[0, z-R_{u}\right]$, if vehicles on $\left[z+R_{u}, L\right]$ are connected, and vehicles separately from $a_{3}$ and $\left[z+R_{u}, L\right]$ are connected, the road interval $[0, L]$ is connected. In this case, the connectivity probability of road interval $[0, L]$ is

$$
p_{1.433}=\operatorname{Pr}\left\{\bar{H}_{\left[0, z-R_{u}\right]}\right\} \cdot \operatorname{Pr}\left\{H_{\left[z+R_{u}, L\right]}\right\} \cdot \operatorname{Pr}\left\{C_{\left[z+R_{u}, L\right]}\right\} \cdot \operatorname{Pr}\left\{C_{\left\{a_{3},\left[z+R_{u}, L\right]\right\}}\right\} .
$$

When there is no vehicle both on $\left[0, z-R_{u}\right]$ and $\left[z+R_{u}, L\right]$, the connectivity probability of the road interval $[0, L]$ is 1 . In this case, the connectivity probability of road interval $[0, L]$ is

$$
p_{1.4 .4}=\operatorname{Pr}\left\{\bar{H}_{\left[0, z-R_{u}\right]}\right\} \cdot \operatorname{Pr}\left\{\bar{H}_{\left[z+R_{u}, L\right]}\right\} .
$$

Thus, the connectivity probability of road interval $[0, L]$ in a-4) is

$$
p_{1.4}=\operatorname{Pr}\left\{\bar{H}_{a_{1}}\right\} \cdot \operatorname{Pr}\left\{\bar{H}_{a_{4}}\right\} \cdot\left(p_{1.4 .1}+p_{1.4 .2}+p_{1.4 .3}+p_{1.4 .4}\right) .
$$

Considering all of above, the connectivity probability of road interval $[0, L]$ in $a)$ is

$$
p_{1}=\operatorname{Pr}\left\{H_{a_{2}}\right\} \cdot \operatorname{Pr}\left\{H_{a_{3}}\right\} \cdot\left(p_{1.1}+p_{1.2}+p_{1.3}+p_{1.4}\right) .
$$

2) There are vehicles on $a_{2}$, but there is no vehicle on $a_{3}$.

In 2 ), if there are vehicles on $\left[z+R_{v}, L\right]$, the distance between any two vehicles separately from $\left[z+R_{v}, L\right]$ and $a_{2}$ is larger than the communication radius of vehicles, the road interval $[0, L]$ is disconnected. Therefore, we only need to consider the connectivity of the interval $[0, z]$ in the case that there is no vehicle on $\left[z+R_{v}, L\right]$. The probability that there is no vehicle on $\left[z+R_{v}, L\right]$ is

$$
\operatorname{Pr}\left\{\bar{H}_{\left[z+R_{v}, L\right]}\right\}=\mathrm{e}^{-\gamma_{2} \cdot\left(L-z-R_{v}\right)} .
$$

When there are vehicles both on $\left[0, z-R_{u}\right]$ and $a_{1}$, if the vehicles on $[0, z]$ are connected, the road interval $[0, L]$ is connected. In this case, the connectivity probability of the road interval $[0, L]$ is

$$
p_{2.1}=\operatorname{Pr}\left\{H_{\left[0, z-R_{u}\right]}\right\} \cdot \operatorname{Pr}\left\{H_{a_{1}}\right\} \cdot \operatorname{Pr}\left\{C_{[0, z]}\right\} .
$$

When there are vehicles on $\left[0, z-R_{u}\right]$, but there is no vehicle on $a_{1}$, if vehicles on $\left[0, z-R_{u}\right]$ are connected, and the vehicles separately from $a_{2}$ and $\left[0, z-R_{u}\right]$ are connected, the road interval $[0, L]$ is connected. In this case, the connectivity probability of the road interval $[0, L]$ is

$$
p_{2.2}=\operatorname{Pr}\left\{H_{\left[0, z-R_{u}\right]}\right\} \cdot \operatorname{Pr}\left\{\bar{H}_{a_{1}}\right\} \cdot \operatorname{Pr}\left\{C_{\left[0, z-R_{u}\right]}\right\} \cdot \operatorname{Pr}\left\{C_{\left\{a_{2},\left[0, z-R_{u}\right]\right\}}\right\} .
$$

When there are vehicles on $a_{1}$, but there is no vehicle on $\left[0, z-R_{u}\right]$, if ve- 
hicles on $\left[z-R_{u}, z\right]$ are connected, the road interval $[0, L]$ is connected. In this case, the connectivity probability of the road interval $[0, L]$ is

$$
p_{2.3}=\operatorname{Pr}\left\{\bar{H}_{\left[0, z-R_{u}\right]}\right\} \cdot \operatorname{Pr}\left\{H_{a_{1}}\right\} \cdot \operatorname{Pr}\left\{C_{\left[z-R_{u}, z\right]}\right\} .
$$

When there is no vehicle both on $\left[0, z-R_{u}\right]$ and $a_{1}$, the connectivity of road interval $[0, L]$ is 1 . In this case, the connectivity probability of the road interval $[0, L]$ is

$$
p_{2.4}=\operatorname{Pr}\left\{\bar{H}_{\left[0, z-R_{u}\right]}\right\} \cdot \operatorname{Pr}\left\{\bar{H}_{a_{1}}\right\} .
$$

Considering all of above, the connectivity probability of road interval $[0, L]$ in b) is

$$
p_{2}=\operatorname{Pr}\left\{H_{a_{2}}\right\} \cdot \operatorname{Pr}\left\{\bar{H}_{a_{3}}\right\} \cdot \operatorname{Pr}\left\{\bar{H}_{\left[z+R_{v}, L\right]}\right\} \cdot\left(p_{2.1}+p_{2.2}+p_{2.3}+p_{2.4}\right) .
$$

3) There are vehicles on $a_{3}$, but there is no vehicle on $a_{2}$.

In 3$)$, if there are vehicles on $\left[0, z-R_{v}\right]$, and the distance between any two vehicles separately from $\left[0, z-R_{v}\right]$ and $a_{3}$ is larger than the communication radius of vehicles, the road interval $[0, L]$ is disconnected. Therefore, we only need to consider the connectivity of $\left[z+R_{v}, L\right]$ in the case that there is no vehicle on $\left[0, z-R_{v}\right]$. The probability that there is no vehicle on $\left[0, z-R_{v}\right]$ is

$$
\operatorname{Pr}\left\{\bar{H}_{\left[0, z-R_{v}\right]}\right\}=\mathrm{e}^{-\gamma_{1} \cdot\left(z-R_{v}\right)} .
$$

When there are vehicles both on $\left[z+R_{u}, L\right]$ and $a_{4}$, if vehicles on $[z, L]$ are connected, the road interval $[0, L]$ is connected. In this case, the connectivity probability of road interval $[0, L]$ is

$$
p_{3.1}=\operatorname{Pr}\left\{H_{\left[z+R_{u}, L\right]}\right\} \cdot \operatorname{Pr}\left\{H_{a_{4}}\right\} \cdot \operatorname{Pr}\left\{C_{[z, L]}\right\} .
$$

When there are vehicles on $\left[z+R_{u}, L\right]$, but there is no vehicle on $a_{4}$, if vehicles on $\left[z+R_{u}, L\right]$ are connected, and the vehicles separately from $a_{3}$ and $\left[z+R_{u}, L\right]$ are connected, the road interval $[0, L]$ is connected. In this case, the connectivity probability of road interval $[0, L]$ is

$$
p_{3.2}=\operatorname{Pr}\left\{H_{\left[z+R_{u}, L\right]}\right\} \cdot \operatorname{Pr}\left\{\bar{H}_{a_{4}}\right\} \cdot \operatorname{Pr}\left\{C_{\left[z+R_{u}, L\right]}\right\} \cdot \operatorname{Pr}\left\{C_{\left\{a_{3},\left[z+R_{u}, L\right]\right\}}\right\} .
$$

When there are vehicles on $a_{4}$, but there is no vehicle on $\left[z+R_{u}, L\right]$, if vehicles on $\left[z, z+R_{u}\right]$ are connected, the road interval $[0, L]$ is connected. In this case, the connectivity probability of road interval $[0, L]$ is

$$
p_{3.3}=\operatorname{Pr}\left\{\bar{H}_{\left[z+R_{u}, L\right]}\right\} \cdot \operatorname{Pr}\left\{H_{a_{4}}\right\} \cdot \operatorname{Pr}\left\{C_{\left[z, z+R_{u}\right]}\right\} .
$$

When there is no vehicle both on $\left[z+R_{u}, L\right]$ and $a_{4}$, the connectivity probability of the road interval $[0, L]$ is 1 . In this case, the connectivity probability of road interval $[0, L]$ is

$$
p_{3.4}=\operatorname{Pr}\left\{\bar{H}_{\left[z+R_{u}, L\right]}\right\} \cdot \operatorname{Pr}\left\{\bar{H}_{a_{4}}\right\} .
$$

Considering all of above, the connectivity probability of road interval $[0, L]$ 
in c) is

$$
p_{3}=\operatorname{Pr}\left\{\bar{H}_{a_{2}}\right\} \cdot \operatorname{Pr}\left\{H_{a_{3}}\right\} \cdot \operatorname{Pr}\left\{\bar{H}_{\left[0, z-R_{v}\right]}\right\} \cdot\left(p_{3.1}+p_{3.2}+p_{3.3}+p_{3.4}\right) .
$$

4) There is no vehicle on $a_{2}$ and $a_{3}$.

In 4), if there are vehicles both on $\left[0, z-R_{v}\right]$ and $\left[z+R_{v}, L\right]$, the distance between any two vehicles separately from $\left[0, z-R_{v}\right]$ and $\left[z+R_{v}, L\right]$ is larger than the communication radius of vehicles, the road interval $[0, L]$ is disconnected. We only need to analyze the connectivity of the case that at most one of the interval $\left[0, z-R_{v}\right]$ and $\left[z+R_{v}, L\right]$ has vehicles.

When there are vehicles on $\left[0, z-R_{v}\right]$, but there is no vehicle on $\left[z+R_{v}, L\right]$, if vehicles on $\left[0, z-R_{v}\right]$ are connected, the road interval $[0, L]$ is connected. In this case, the connectivity probability of road interval $[0, L]$ is

$$
p_{4.1}=\operatorname{Pr}\left\{H_{\left[0, z-R_{v}\right]}\right\} \cdot \operatorname{Pr}\left\{\bar{H}_{\left[z+R_{v}, L\right]}\right\} \cdot \operatorname{Pr}\left\{C_{\left[0, z-R_{v}\right]}\right\},
$$

where

$$
\operatorname{Pr}\left\{H_{\left[0, z-R_{v}\right]}\right\}=1-\mathrm{e}^{-\gamma_{1} \cdot\left(z-R_{v}\right)}, \operatorname{Pr}\left\{C_{\left[0, z-R_{v}\right]}\right\}=\operatorname{Pr}\left\{\gamma_{1}, R_{v}, z-R_{v}\right\} .
$$

When there are vehicles on $\left[z+R_{v}, L\right]$, but there is no vehicle on $\left[0, z-R_{v}\right]$, if vehicles on $\left[z+R_{v}, L\right]$ are connected, the road interval $[0, L]$ is connected. In this case, the connectivity probability of road interval $[0, L]$ is

$$
p_{4.2}=\operatorname{Pr}\left\{\bar{H}_{\left[0, z-R_{v}\right]}\right\} \cdot \operatorname{Pr}\left\{H_{\left[z+R_{v}, L\right]}\right\} \cdot \operatorname{Pr}\left\{C_{\left[z+R_{v}, L\right]}\right\},
$$

where

$$
\operatorname{Pr}\left\{H_{\left[z+R_{v}, L\right]}\right\}=1-\mathrm{e}^{-\gamma_{2} \cdot\left(L-z-R_{v}\right)}, \operatorname{Pr}\left\{C_{\left[z+R_{v}, L\right]}\right\}=\operatorname{Pr}\left\{\gamma_{2}, R_{v}, L-z-R_{v}\right\} .
$$

When there is no vehicle both on $\left[0, z-R_{v}\right]$ and $\left[z+R_{v}, L\right]$, the road interval $[0, L]$ is connected. In this case, the connectivity probability of road interval $[0, L]$ is

$$
p_{4.3}=\operatorname{Pr}\left\{\bar{H}_{\left[0, z-R_{v}\right]}\right\} \cdot \operatorname{Pr}\left\{\bar{H}_{\left[z+R_{v}, L\right]}\right\} .
$$

Considering all of above, the connectivity probability of road interval $[0, L]$ in $d$ ) is

$$
p_{4}=\operatorname{Pr}\left\{\bar{H}_{a_{2}}\right\} \cdot \operatorname{Pr}\left\{\bar{H}_{a_{3}}\right\} \cdot\left(p_{4.1}+p_{4.2}+p_{4.3}\right) .
$$

According to analysis of 1)-4), we can obtain the connectivity probability of road interval $[0, L]$ as follows

$$
p=\frac{1}{L-2 R_{u}} \int_{R_{u}}^{L-R_{u}}\left(p_{1}+p_{2}+p_{3}+p_{4}\right) \mathrm{d} z .
$$

\section{Numerical Results}

In this section, we perform simulation using event-driven and Monte Carlo methods by Matlab tool to verify the proposed analysis model. The parameter values are decided according to the assumption vehicular environment of statistics 
observations. Then according to the numerical results, we analyze the impacts of several parameters on the connectivity probability. Each simulation result is an average over 10,000 times. It is seen from Figures 3-5 the analytical results are very close to the simulation results.

Figure 3 shows the impacts of $\lambda_{1}, \lambda_{2}$ and $\alpha$ on the network connectivity probability.

With the increasing of $\lambda_{1}, \lambda_{2}$ and $\alpha$, the connectivity probability also increases. This is because larger values of $\lambda_{1}, \lambda_{2}$ and $\alpha$ make the number of vehicles in unit road length becoming larger which reduces the distance of neighbor vehicles, and resulting in a larger connectivity probability of neighbor vehicles.

Figure 4 shows the impacts of $L$ and $v$ on the network connectivity probability. With the increasing of $L$ and $V$, the connectivity probability decreases. This is because with the increase of $L$, if the arrival rates do not change, there are fewer

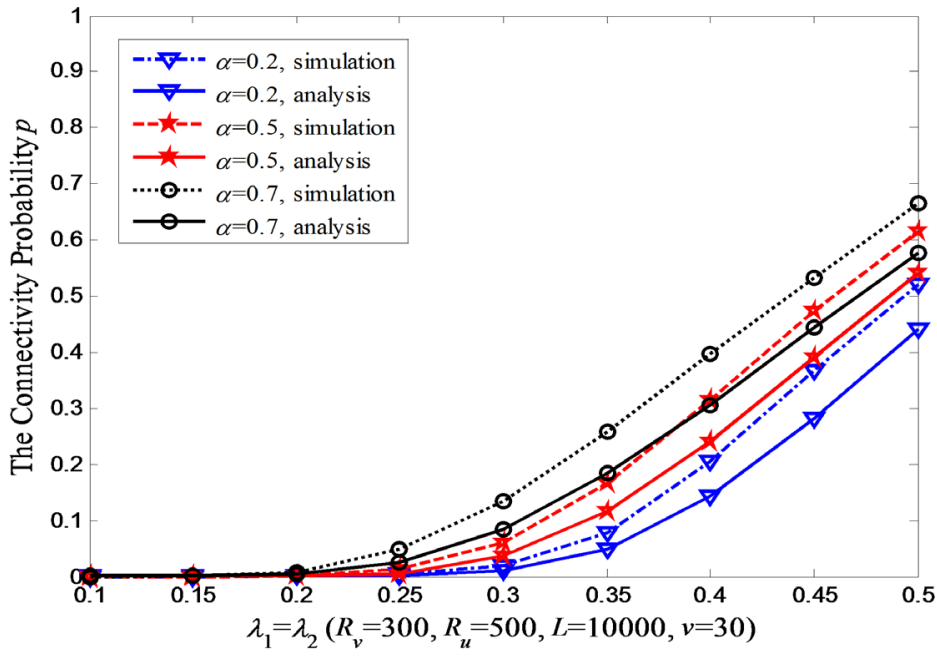

Figure 3. Impacts of $\lambda_{1}, \lambda_{2}$ and $\alpha$ on the connectivity probability.

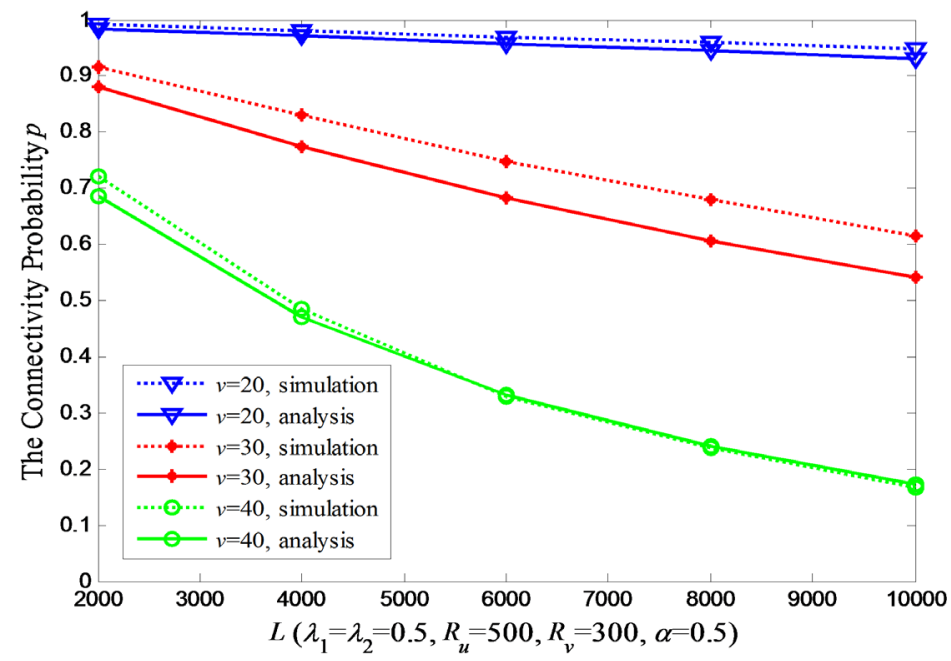

Figure 4. Impacts of $L$ and $v$ on the connectivity probability. 


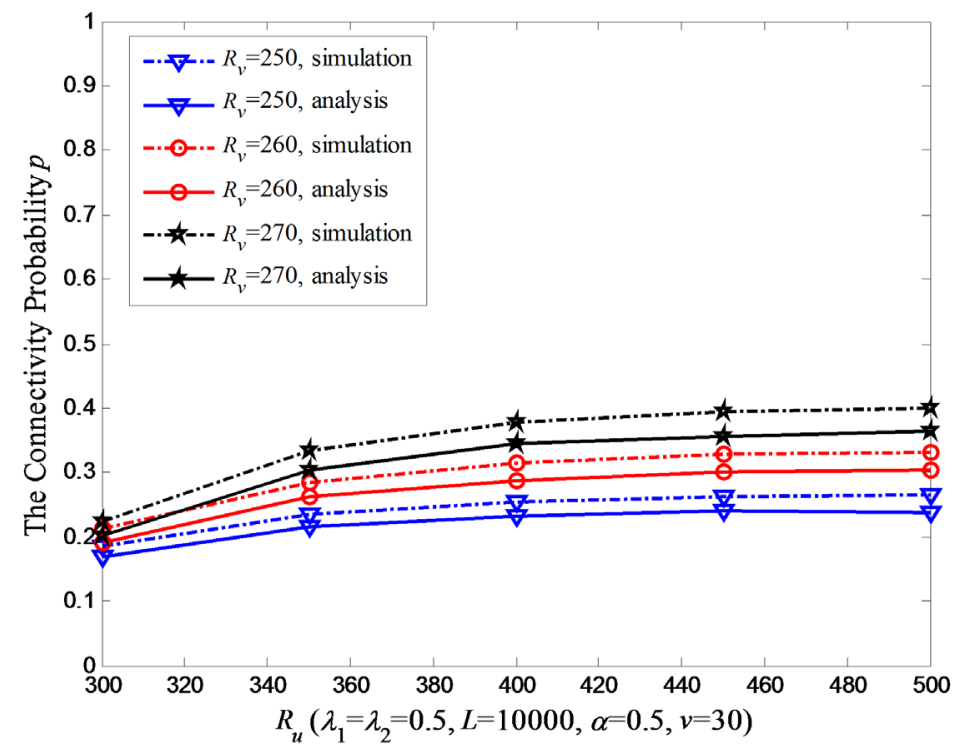

Figure 5. Impacts of $R_{u}$ and $R_{V}$ on the connectivity probability.

vehicles on the unit length of the highway road and the distance between two neighbor vehicles becomes larger. As a result, the connectivity probability decreases. Similarly, with the increase of $v$, if the arrival rates do not change, there are fewer vehicles on the unit length of the highway road and the distance between two neighbor vehicles becomes larger which leads to the decreasing of the network connectivity probability.

Figure 5 shows the impacts of $R_{u}$ and $R_{V}$ on the connectivity probability. With the increasing of $R_{u}$ and $R_{v}$ the connectivity probability also increases. This is because a larger value of $R_{u}$ and $R_{V}$ makes two neighbor vehicles have a larger chance to communicate with each other.

\section{Conclusion}

In this paper, we build an analytical model to study the network connectivity of highway scenario with one entry/exit and one RSU. In building the analytical model, we divide the highway road into several road intervals, and analyze both the connectivity of each road interval and the connectivity of neighbor road interval. The analytical model is verified by using simulation tools, and the analytical model can be used to analyze the impacts of several parameters on the network connectivity. The built network connectivity analytical model can be used to provide a reference for the highway scenario with multiple entries/exits and multiple RSUs which are our future work.

\section{Acknowledgements}

This work is supported by the National Natural Science Foundation of China (No. 61701202 and No. 61901196), the Talent Introduction Project of Jiangsu University of Technology (No. KYY18008), the Project on natural science research in Jiangsu Province universities (No. 19KJB510026). 


\section{Conflicts of Interest}

The authors declare no conflicts of interest regarding the publication of this paper.

\section{References}

[1] Khabazian, M. and Mustafa, K.M.A. (2008) A Performance Modeling of Connectivity in Vehicular Ad Hoc Networks. IEEE Transactions on Vehicular Technology, 57, 2440-2450. https://doi.org/10.1109/TVT.2007.912161

[2] Wang, Y. and Zheng, J. (2016) A Connectivity Analytical Model for a Highway with an Entrance/Exit in Vehicular Ad Hoc Networks. 2016 IEEE International Conference on Communications (ICC), Kuala Lumpur, 22-27 May 2016, 1-6. https://doi.org/10.1109/ICC.2016.7510773

[3] Reis, A.B., Sargento, A. and Tonguz, O.K. (2014) Deploying Roadside Units in Sparse Vehicular Networks: What Really Works and What Does Not. IEEE Transactions on Vehicular Technology, 63, 2794-2806.

https://doi.org/10.1109/TVT.2013.2292519

[4] Abdrabou, A. and Zhuang, W. (2011) Probabilistic Delay Control and Road Side Unit Placement for Vehicular Ad Hoc Networks with Disrupted Connectivity. IEEE Journal on Selected Areas in Communications, 29, 129-139.

https://doi.org/10.1109/JSAC.2011.110113

[5] Neelakantan, P.C. and Babu, A.V. (2013) Connectivity Analysis of Vehicular Ad Hoc Networks from a Physical Layer Perspective. Wireless Personal Communication, 71, 45-70. https://doi.org/10.1007/s11277-012-0795-Z

[6] Shao, C., Leng, S., Leng, S., Zhang, Y., Vinel, A. and Jonsson, M. (2015) Performance Analysis of Connectivity Probability and Connectivity-Aware MAC Protocol Design for Platoon-Based VANETs. IEEE Transactions on Vehicular Technology, 64, 5596-5609. https://doi.org/10.1109/TVT.2015.2479942

[7] Kwon, S., Kim, Y. and Shroff, N.B. (2016) Analysis of Connectivity and Capacity in 1-D Vehicle-to-Vehicle Networks. IEEE Transactions on Wireless Communications, 15, 8182-8194. https://doi.org/10.1109/TWC.2016.2613078

[8] Sou, S.-I. and Tonguz, O.K. (2011) Enhancing VANET Connectivity through Roadside Units on Highways. IEEE Transactions on Vehicular Technology, 60, 3586-3602. https://doi.org/10.1109/TVT.2011.2165739 